\title{
Seeing Is Feeding for the Frugivorous Bird Brown-Eared Bulbul (Microscelis amaurotis)
}

\author{
Takeshi Honda, ${ }^{1}$ Jun-ichi Tsuboi, ${ }^{2}$ and Hiroshi Kuwata ${ }^{1}$ \\ ${ }^{1}$ Yamanashi Prefecture Agricultural Research Center, Kai, Yamanashi 400-0105, Japan \\ ${ }^{2}$ National Research Institute of Aquaculture, Fisheries Research Agency, Nikko, Tochigi 321-1661, Japan \\ Correspondence should be addressed to Takeshi Honda; honda-yvj@pref.yamanashi.lg.jp
}

Received 25 August 2015; Accepted 21 October 2015

Academic Editor: George A. Lozano

Copyright (C) 2015 Takeshi Honda et al. This is an open access article distributed under the Creative Commons Attribution License, which permits unrestricted use, distribution, and reproduction in any medium, provided the original work is properly cited.

\begin{abstract}
We examined feeding behavior by visually blocking fruit to establish a new theory of bird damage management for agricultural practices. Partly or fully invisible clusters of grapes were fixed on a perch. The birds selectively pecked the clearly visible part of the half-visible bag at a pecking count rate of $0.94-1.00$ (95\% CI). Half-visible bags allowed the birds to look inside like a skirt and detect the initially hidden portions of grapes, which were covered with opaque white bags. However, very few birds pecked at the white bags that were partially covering the grapes. That is, very few birds attempted to eat covered but easily detectable fruits. Only five birds gravitated toward the grapes in the completely covered nontranslucent bags, but they never pecked at them. Our results show that visual blocking could be a promising new technique to prevent bird damage.
\end{abstract}

\section{Introduction}

Birds damage agricultural productions; however, effective countermeasures have not been developed. Several techniques are used to deter birds, such as sonic, visual, olfactory, and gustatory deterrents. However, almost all methods are impractical because they result in habituation (e.g., distress calls $[1,2]$, visual deterrents [3-6], olfactory stimuli [7], and chemical repellents [8]). The fact that existing techniques do not perform satisfactorily indicates the necessity of newly developed techniques based on original principles. Here, we address damage management from a pure ecological viewpoint, namely, seed dispersion by birds.

Relationships between fruiting plants and avian seed dispersers have been well studied, and seed dispersers are believed to have exerted selective pressure on a diverse array of plant traits [9-14]. These traits include fruit nutritive quality [15], size [16], density (distance between fruits) [17, 18], and color [13]. During the 1980s and early 1990s, the most influential hypothesis that aimed at explaining how seed dispersers influence the evolution of plant coloration assumed that birds have strong preferences for certain colors (i.e., the color hypothesis [19]). Although some studies have reported particular color preferences in seed dispersers, these studies have produced inconsistent results [20-24]. Frugivores use fruit conspicuousness, which is the result of spectral contrasts between fruits and their backgrounds (i.e., the contrast hypothesis [25-28]). Fruit color patterns are adaptations that maximize color contrasts with background leaves, thereby attracting avian seed dispersers [25]. The contrast hypothesis assumes that birds can forage using their sense of vision, and the importance of visual signals has been well reported [25-29]. However, the effect of visual blocking has not been documented.

The importance of visual detection has also been supported by another study. The neighborhood effect, proposed by Sargent [18], refers to the observation that densely borne fruits are more likely to have their seeds dispersed. OrtizPulido et al. [16] reported that larger fruit crops had higher levels of fruit removal. High fruit density and large crop size both improve the visibility of some fruits and enhance seed dispersion, so fruit visibility would be one of the main factors contributing to seed dispersion because visual stimuli (i.e., visible versus out of view) would directly affect 
feeding behavior. If feeding behavior requires visual stimuli, covered fruits have a reduced chance of seed dispersion. Therefore, artificial visual blocking may also prevent bird damage to cultivated types of fruit. This perspective should help establish new techniques for bird damage management.

In this study, we hypothesize that the feeding behavior of the frugivorous brown-eared bulbul bird (Microscelis amaurotis) is directly connected to visual stimuli (i.e., seeing is feeding). If feeding behavior is based on sight, visually blocking fruits should prevent birds from feeding on them. To test the hypothesis, partly hidden grapes were used. Specifically, a cluster of grapes was covered, with the upper or lower half of the cluster in a clear bag and the other half out of view inside a devitrified white paper bag. If our assumption is true, visual blocking could act as a countermeasure against bird damage. The brown-eared bulbul was targeted because these species (and crows) (Corvus corone and C. macrorhynchos) cause most of the damage in this study area $[30,31]$. In addition, the paper bag is commonly used for external qualities, disease control, and pest control for fruit in Asia [32-34]. Crows easily and frequently break devitrified bags and wrapping film [30]; therefore, this paper bag could not effectively protect fruit from birds and was not used for damage management. Barely visible lines [35] enabled us to evaluate the usefulness of visual blocking techniques for frugivorous birds.

\section{Materials and Methods}

2.1. Study Area. Fieldwork for this study was conducted in the winter, from January 11 to January 25, 2011, at the Yamanashi Prefecture Agricultural Research Center, Japan. The research was undertaken during this season because natural fresh fruits are generally unavailable in the winter. As a result, birds are more easily attracted to fruits in the winter than in other seasons. We attempted to attract birds in summer, but only a few birds were observed. A river, paddy fields, orchards, and urban lands surround the study area. Browneared bulbuls are the dominant frugivorous birds in the study area throughout the year [36, 37]. Occasionally, we also observed white-cheeked starlings (Sturnus cineraceus), dusky thrushes (Turdus eunomus), Eurasian tree sparrows (Passer montanus), Oriental turtle doves (Streptopelia orientalis), rock doves (Columba livia), carrion crows (Corvus corone), and large-billed crows (Corvus macrorhynchos).

2.2. Study Design. A $10 \mathrm{~mm} \varphi, 40 \mathrm{~cm}$ long glass fiber perch was set at $1.2 \mathrm{~m}$ high with a grape cluster attached (cultivar: Steuben, color: dark purple, length: mean $=174 \mathrm{~mm}$, $\mathrm{sd}=16$, and weight: mean $=343 \mathrm{~g}$, sd $=22$; Figure 1). This study used grapes because a compound raceme (i.e., cluster of fruits) can be selectively and partly covered. In this study, we set two grape feeding stations $140 \mathrm{~m}$ apart. Prior to the experiment, unobscured grapes were fixed to the perches without any treatment for 5 days to habituate birds to the perches. During the experimental period, we set up three treatment groups. Clusters of grapes were all supported from above, hanging like a natural cluster of grapes and fixed to the perch in three ways: (1) with the grape cluster uncovered and visible

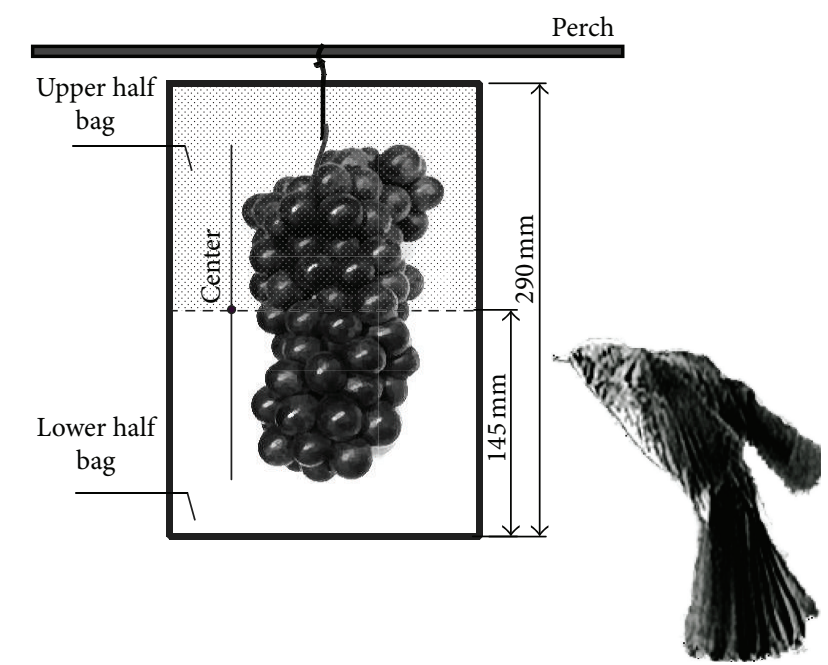

FIgURE 1: This study design figure shows a cluster of grapes suspended from a perch. Three basic test methods were used: (1) no bag present (uncovered); (2) half covered/half-visible grape cluster (half-visible bag); and (3) the entire cluster of grapes inside a white bag (full bag). The illustration shows a "half-visible bag," with the upper half white (black shaded in this figure) and the lower half made of clear film. The white paper bag covered grapes like a skirt; therefore, the birds could look into the white paper bag through the clear film (the lower half bag). Full bags were completely made of white paper. Birds fed on uncovered grapes but could not feed directly on grapes that were covered in the "half-visible bag" or the "full bag."

(uncovered grapes); (2) with the cluster of grapes covered by two kinds of half bags (half-visible bag), where the clear half bag allowed the birds to see either the upper or lower half of a grape cluster, while the white half bag partially obscured the grape cluster; and (3) with the entire cluster of grapes out of view inside a white-colored nontranslucent waterproof bag (full bag). A small drain hole was made in the bottom of each bag. During the 15-day study period, these three treatment groups were set up five times on each perch in random order so the sequence of the treatments had no pattern. The uncovered grapes were used as a control. Although the halfvisible bags covered half of a grape cluster, birds could look inside the white half bag and see the covered part of the cluster through a space between the grapes and the white half bag. For example, in one setup, hovering birds could look into the lower half-visible bag because the upper white half of the bag covered the grapes like a skirt and the lower half of the bag covered the grapes like a see-through dress. The half-visible bag treatment was used to test whether the birds would attempt to feed on the grapes in the white papercovered half of the bag (i.e., the covered part of the fruit) by remembering and inferring that the fruit was covered by the half-sized white paper bag. The full bag treatment was also used to test whether the birds would attempt to feed on the grape clusters that were fully covered in the white bag.

To monitor bird behavior, a video camera (HDR-CX370V, SONY, Tokyo, Japan) was set up $2 \mathrm{~m}$ from the grapes. The video camera operated from 8:30 a.m. to 4 p.m. (7.5 hours). 
A black wire line was hung above the perch to deter crows [35] because we wanted to observe the behavior of the frugivorous bulbul bird. The thin black line was barely visible, and crows had a higher risk of collision. This collision risk was intended to deter crows only [35], as crows could have destroyed our bags. The number and species of birds attracted and the pecking count data were extracted from the video cameras. Pecking counts of uncovered grapes were counted directly, but pecking counts of the grape clusters covered by a half-visible bag or full bag were measured by counting the number of pecking attempts directed at either bag. In addition, the pecking count for the partially visible grape clusters (half-visible bag) was calculated separately from pecking attempts at either the white paper or the clear film.

2.3. Statistical Analysis. For the three treatment groups, differences in the attracted bird counts were tested using a generalized linear mixed model (GLMM; error distribution: Poisson, random factor: ID of feeding sites) and Holm method. Pecking count data for the half-visible bags were treated as proportional data (pecking counts of the visible part of the grape/total pecking counts), and these proportional data were analyzed using the GLMM (error distribution: binomial, random factor: ID of feeding sites). Whelan and Willson [38] reported that birds preferred foods that were easily accessible from a perch, which suggests a bias toward the upper portion of the half bags. Therefore, we made separate model estimations for the two groups (i.e., upper and lower half-visible bags). All statistical analyses were performed using R 2.13.0 [39] and library glmmML.

\section{Results}

The bird species that used the perch and hovered for feeding were the brown-eared bulbul $(n=1007)$, the dusky thrush ( $n$ $=26$ ), and the bull-headed shrike (Lanius bucephalus) ( $n=$ 1). Only the brown-eared bulbuls pecked the half-visible bags or full bags, but they never broke the bags. We used only brown-eared bulbul pecking data because dusky thrush and shrike never pecked the covered fruits (i.e., half-visible bag or full bag); our treatments protected the fruit from these birds even if half of the fruit was visible. The order of birds numbers attracted to each test site each day in each treatment group was uncovered $>$ half-visible bag $>$ full bag (Figure 2, GLMM and Holm method; $p<0.05$ ). The full bag attracted five feeding attempts by bulbuls, but these birds never pecked at the bag.

Upper or lower half-visible bags attracted 26 and 46 birds, respectively. Of 338 attempts at pecking half-visible bags, only one attempt was made at pecking the white half bag. Estimated $95 \%$ confidence intervals for pecking the visible part/total pecking were $0.98-0.99$ and $0.94-1.00$ for the upper and lower half-visible bags, respectively (Figure 3). The results indicated that bulbul pecking behavior is strongly biased toward the visible part of a grape cluster.

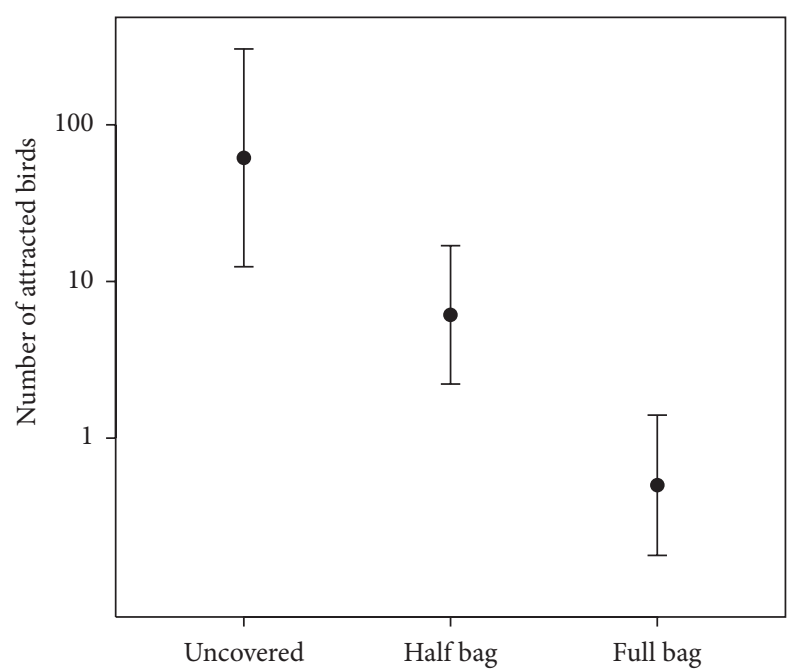

FIGURE 2: The number of birds (log) attracted to each treatment per day for each treatment group; "uncovered," "half bag," and "full bag" refer to an uncovered grape cluster, a cluster covered with a bag, half of which is clear and half of which is opaque white, and an opaque white bag, respectively. Error bars indicate 95\% confidence intervals (GLMM; error distribution: Poisson).

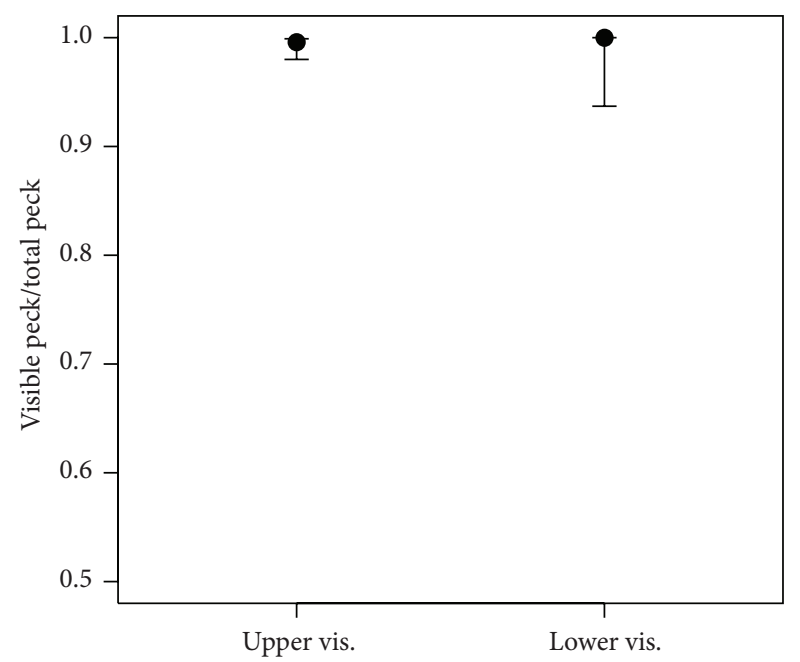

FIgURE 3: The probability of pecking the clear part of a two-part bag, with half clear and half white. Fruits were covered with halfclear bags in which the upper or lower half was opaque (half-visible bag; see Figure 1). The probabilities were estimated as pecking counts on the clear part divided by the total pecking count. The $x$-axis shows the treatment; "upper vis." and "lower vis." mean that the upper or lower half part was the clear part, through which fruit were visible. Error bars indicate 95\% confidence intervals (GLMM; error distribution: binomial).

\section{Discussion}

The results confirm that feeding behavior of the browneared bulbul is directly linked to visual stimuli. The lower confidence limit of pecking the visible part/total pecking was 0.94 , close to 1 . In addition, the bulbuls never pecked fruits that were covered by a full bag, even though repeatedly 
birds fed on uncovered fruits that were located in the same position as the covered and not visible fruit. The results of the experiments using half-clear and half-white bags (i.e., halfvisible bags) suggest that a visual stimulus induces feeding behavior. Half-clear/half-white bags hid half of the fruit cluster, but not perfectly. Birds could see inside the white half bag by looking into a space between the fruit and the invisible bag like a skirt. Birds could see a piece of the covered fruit cluster and recognize the covered part of the fruit; however, only one bird pecked at the white half of a bag. The fact that almost all of the pecking behavior was targeted at part of a bag with clear fruit visibility showed the importance of visual stimuli. Frugivorous bulbul birds would start feeding on visible fruit the moment they visually detected the fruit, but they never started to feed based on the memory of previously observed fruit. The test using fruit inside an all-white bag also shows that the frugivorous bulbul bird did not use memory for feeding. We conclude that frugivorous bulbul birds feed on fruit based only on visual stimuli; that is, seeing is feeding for the frugivorous bulbul bird. Perhaps frugivorous birds depend on their visual senses for feeding because birds have remarkable visual abilities [40].

In this study, we observed the feeding behavior of only one frugivorous species. However, Bernhardt and Seamans [41] also showed that red-winged blackbirds (Agelaius phoeniceus) selectively fed on visible foods. They reported that long husks made it difficult for blackbirds to peck at sweet corn and showed that blackbirds fed less frequently on hardly visible sweet corn that was covered by long husks. The behavior of red-winged blackbirds also shows the importance of visual detection and supports our hypothesis.

Though this study clearly showed the necessity of visual stimuli for feeding, further study is needed to generalize this new technique. Our only target species was the brown-eared bulbul, which is the species that causes the most damage. For practical use, other applicable bird species should be studied. We do not believe this technique can be applied to all birds. For example, in insect pest management, one pesticide targets only a limited number of insect pests, and, in order to cover several insect pests, many kinds of pesticides are developed. Bird damage management should function in the same way as insect pest management. Indeed, this study employed a combined application of visual blocking techniques for frugivorous birds and a barely visible line for crows. Integrated wildlife management is therefore needed [42]. Other than crows, there were some exceptions to our results. Though this study revealed the importance of direct visual contact with fruit, some other bird species peck invisible foods $[43,44]$. When starlings (Sturnus vulgaris) peck the soil, most food is not visible [43]. Frugivorous birds would not have to search for fruits, whereas ground-feeding birds may have to perform searching tasks. This is because fruiting plants would be expected to develop a place to exhibit fruits (the contrast hypothesis [25-28]).

This study showed that visual blocking is useful for preventing fruit damage caused by frugivorous birds. This technique is also easily applicable, as farmers usually use paper bags for fruit in Asia. It is important to note the combination of this technique with a barely visible line for crows [35]. Though we demonstrated the viability of a new technique based on a novel principle, more research is needed, especially for other applicable bird species.

\section{Disclosure}

This study did not use animals directly.

\section{Conflict of Interests}

The authors declare that there is no conflict of interests regarding the publication of this paper.

\section{Acknowledgments}

The authors thank Mrs. Yoko Koshimizu for her laboratory assistance. They also thank Dr. Martin Schaefer for his useful comments.

\section{References}

[1] R. J. Johnson, P. H. Cole, and W. W. Stroup, "Starling response to three auditory stimuli," Journal of Wildlife Management, vol. 49, no. 3, pp. 620-625, 1985.

[2] M. Bomford and P. H. O'Brien, "Sonic deterrents in animal damage control: a review of device tests and effectiveness," Wildlife Society Bulletin, vol. 18, no. 4, pp. 411-422, 1990.

[3] B. F. Blackwell, G. E. Bernhardt, and R. A. Dolbeer, "Lasers as nonlethal avian repellents," Journal of Wildlife Management, vol. 66, no. 1, pp. 250-258, 2002.

[4] W. P. Gorenzel, B. F. Blackwell, G. D. Simmons, T. P. Salmon, and R. A. Dolbeer, "Evaluation of lasers to disperse American crows, Corvus brachyrhynchos, from urban night roosts," International Journal of Pest Management, vol. 48, no. 4, pp. 327-331, 2002.

[5] P. P. Woronecki, "Effect of ultrasonic, visual, and sonic devices on pigeon numbers in a vacant building," in Proceedings of the 13th Vertebrate Pest Conference, pp. 266-272, Monterey, Calif, USA, March 1988.

[6] J. L. Belant, P. P. Woronecki, R. A. Dolbeer, and T. W. Seamans, "Ineffectiveness of five commercial deterrents for nesting starlings," Wildlife Society Bulletin, vol. 26, no. 2, pp. 264-268, 1998.

[7] R. A. Dolbeer, M. A. Link, and P. P. Woronecki, "Naphthalene shows no repellency for starlings," Wildlife Society Bulletin, vol. 16, no. 1, pp. 62-64, 1988.

[8] J. Tracey, M. Bomford, Q. Hart, G. Saunders, and R. Sinclair, Managing Bird Damage to Fruit and Other Horticultural Crops, Bureau of Rural Sciences, Canberra, Australia, 2007.

[9] D. W. Snow, "Evolutionary aspects of fruit-eating by birds," Ibis, vol. 113, no. 2, pp. 194-202, 1971.

[10] C. M. Herrera, "Adaptation to frugivory of mediterranean avian seed dispersers," Ecology, vol. 65, no. 2, pp. 609-617, 1984.

[11] M. I. Manzur and S. P. Courtney, "Influence of insect damage in fruits of hawthorn on bird foraging and seed dispersal," Oikos, vol. 43, no. 3, pp. 265-270, 1984.

[12] J. M. Cramer, M. L. Cloud, N. C. Muchhala, A. E. Ware, B. H. Smith, and G. Bruce Williamson, "A test of the bicolored fruit display hypothesis: berry removal with artificial fruit flags," Journal of the Torrey Botanical Society, vol. 130, no. 1, pp. 30-33, 2003. 
[13] C. R. Gosper, C. D. Stansbury, and G. Vivian-Smith, "Seed dispersal of fleshy-fruited invasive plants by birds: contributing factors and management options," Diversity and Distributions, vol. 11, no. 6, pp. 549-558, 2005.

[14] K. C. Burns, E. Cazetta, M. Galetti, A. Valido, and H. M. Schaefer, "Geographic patterns in fruit colour diversity: do leaves constrain the colour of fleshy fruits?" Oecologia, vol. 159, no. 2, pp. 337-343, 2009.

[15] E. W. Stiles, "Patterns of fruit presentation and seed dispersal in bird-disseminated woody plants in the eastern deciduous forest," The American Naturalist, vol. 116, no. 5, pp. 670-688, 1980.

[16] R. Ortiz-Pulido, Y. V. Albores-Barajas, and S. A. Díaz, "Fruit removal efficiency and success: influence of crop size in a neotropical treelet," Plant Ecology, vol. 189, no. 1, pp. 147-154, 2007.

[17] D. J. Levey, T. C. Moermond, and J. S. Denslow, "Fruit choice in neotropical birds: the effect of distance between fruits on preference patterns," Ecology, vol. 65, no. 3, pp. 844-850, 1984.

[18] S. Sargent, "Neighborhood effects on fruit removal by birds: a field experiment with Viburnum dentatum (Caprifoliaceae)," Ecology, vol. 71, no. 4, pp. 1289-1298, 1990.

[19] E. Cazetta, H. M. Schaefer, and M. Galetti, "Why are fruits colorful? The relative importance of achromatic and chromatic contrasts for detection by birds," Evolutionary Ecology, vol. 23, no. 2, pp. 233-244, 2009.

[20] M. F. Willson, D. A. Graff, and C. J. Whelan, "Color preferences of frugivorous birds in relation to the colors of fleshy fruits," The Condor, vol. 92, no. 3, pp. 545-555, 1990.

[21] K. G. Murray, K. Winnett-Murray, E. A. Cromie, M. Minor, and E. Meyers, "The influence of seed packaging and fruit color on feeding preferences of American robins," Vegetatio, vol. 107-108, no. 1, pp. 217-226, 1993.

[22] J. P. Gionfriddo and L. B. Best, "Grit color selection by house sparrows and northern bobwhites," Journal of Wildlife Management, vol. 60, no. 4, pp. 836-842, 1996.

[23] A. Traveset, N. Riera, and R. E. Mas, "Ecology of fruit-colour polymorphism in Myrtus communis and differential effects of birds and mammals on seed germination and seedling growth," Journal of Ecology, vol. 89, no. 5, pp. 749-760, 2001.

[24] K. D. Whitney, "Linking frugivores to the dynamics of a fruit color polymorphism," American Journal of Botany, vol. 92, no. 5, pp. 859-867, 2005.

[25] K. C. Burns and J. L. Dalen, "Foliage color contrasts and adaptive fruit color variation in a bird-dispersed plant community," Oikos, vol. 96, no. 3, pp. 463-469, 2002.

[26] V. Schmidt, H. M. Schaefer, and H. Winkler, "Conspicuousness, not colour as foraging cue in plant-animal signalling," Oikos, vol. 106, no. 3, pp. 551-557, 2004.

[27] H. M. Schaefer, D. J. Levey, V. Schaefer, and M. L. Avery, "The role of chromatic and achromatic signals for fruit detection by birds," Behavioral Ecology, vol. 17, no. 5, pp. 784-789, 2006.

[28] H. M. Schaefer, V. Schaefer, and M. Vorobyev, "Are fruit colors adapted to consumer vision and birds equally efficient in detecting colorful signals?” American Naturalist, vol. 169, pp. 159-169, 2007.

[29] J. M. Facelli, "Experimental evaluation of the foliar flag hypothesis using fruits of Rhus glabra (L.)," Oecologia, vol. 93, no. 1, pp. 70-72, 1993.

[30] Y. Eguchi, S. Miura, and M. Fujioka, Cyoujuugai Taisaku no Tebiki, Japan Plant Protection Association, Tokyo, Japan, 2002 (Japanese).
[31] M. Fujioka and K. Nakamura, Cyougai no Fusegikata, Ie-noHikari Association, Tokyo, Japan, 2000 (Japanese).

[32] Y. Noguchi and S. Kawada, Nougaku Daijiten, Youkendo, Tokyo, Japan, 1987 (Japanese).

[33] C. Huang, B. Yu, Y. Teng et al., "Effects of fruit bagging on coloring and related physiology, and qualities of red Chinese sand pears during fruit maturation," Scientia Horticulturae, vol. 121, no. 2, pp. 149-158, 2009.

[34] D. Sarker, M. M. Rahman, and J. C. Barman, "Efficiency of different bagging materials for the control of mango fruit fly," Bangladesh Journal of Agricultural Research, vol. 34, pp. 153-168, 2009.

[35] T. Honda, "Line color affects the collision risk and deterrence of crows," Journal of Ethology, vol. 30, no. 1, pp. 11-14, 2012.

[36] M. Brazil, Birds of East Asia: China, Taiwan, Korea, Japan, and Russia, Princeton University Press, Oxford, UK, 2009.

[37] R. Hirata, S. Hirai, K. Hata, and K. Sone, "Observation of the autumn migration of the brown-eared bulbul, Hypsipetes amaurotis, on the Korimoto campus of Kagoshima University," Research Bulletin of the Kagoshima University Forests, vol. 36, pp. 23-27, 2009 (Japanese).

[38] C. J. Whelan and M. F. Willson, "Fruit choice in migrating North American birds: field and aviary experiments," Oikos, vol. 71, no. 1, pp. 137-151, 1994.

[39] R Development Core Team, "R: A Language and Environment for Statistical Computing," 2011, http://www.R-project.org/.

[40] E. J. Gerl and M. R. Morris, "The causes and consequences of color vision," Evolution: Education and Outreach, vol. 1, no. 4, pp. 476-486, 2008.

[41] G. E. Bernhardt and T. W. Seamans, "Red-winged blackbird feeding behavior on two sweet corn cultivars," Wildlife Society Bulletin, vol. 18, no. 1, pp. 83-86, 1990.

[42] M. R. Conover, Resolving Human-Wildlife Conflicts: The Science of Wildlife Damage Management, CRC Press, Boca Raton, Fla, USA, 2002.

[43] J. Stevens, "Foraging success of adult and juvenile starlings Sturnus vulgaris: a tentative explanation for the preference of juveniles for cherries," Ibis, vol. 127, no. 3, pp. 341-347, 1985.

[44] K. N. Mouritsen, "Day and night feeding in Dunlins Calidris alpina: choice of habitat, foraging technique and prey," Journal of Avian Biology, vol. 25, no. 1, pp. 55-62, 1994. 

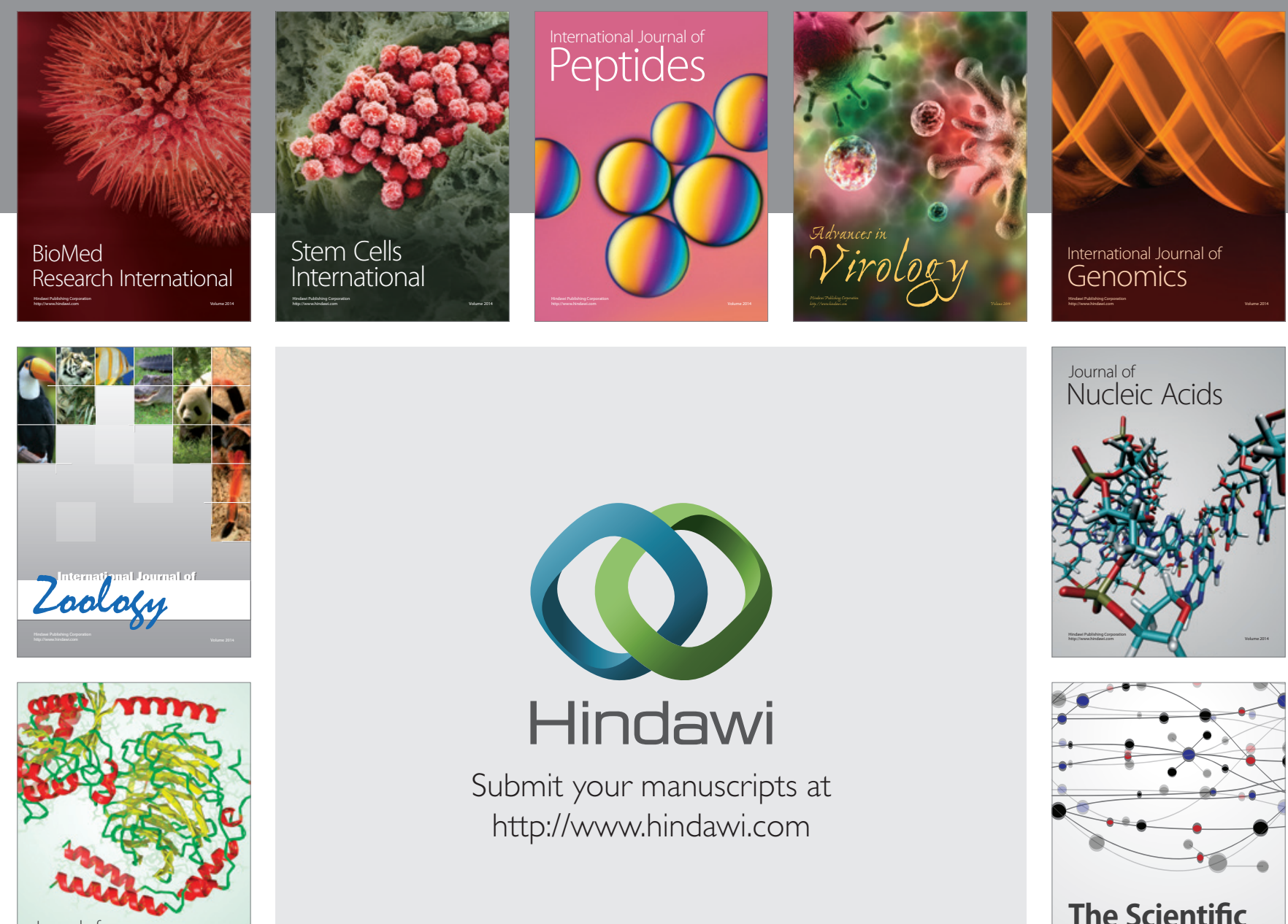

Submit your manuscripts at

http://www.hindawi.com

Journal of
Signal Transduction
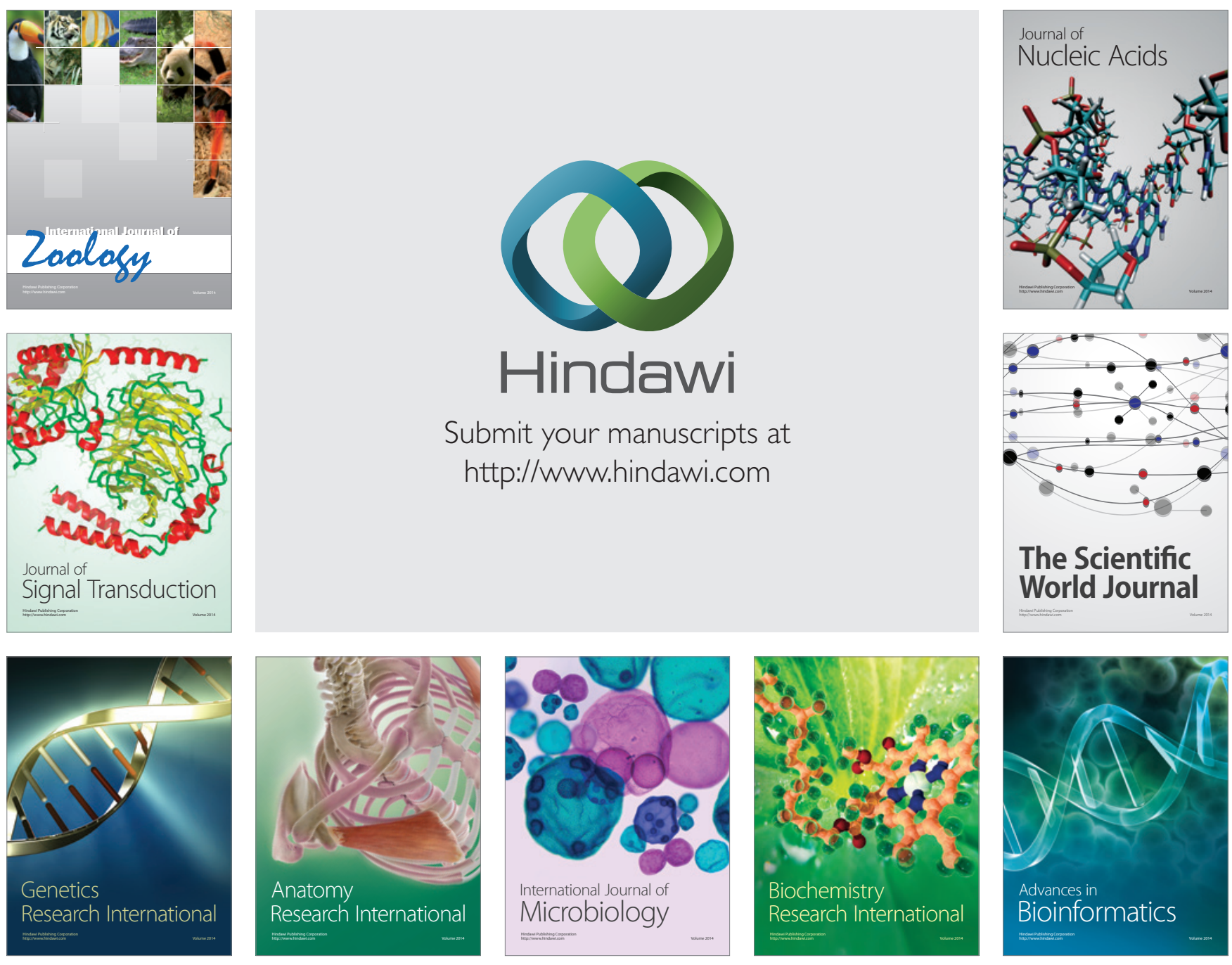

The Scientific World Journal
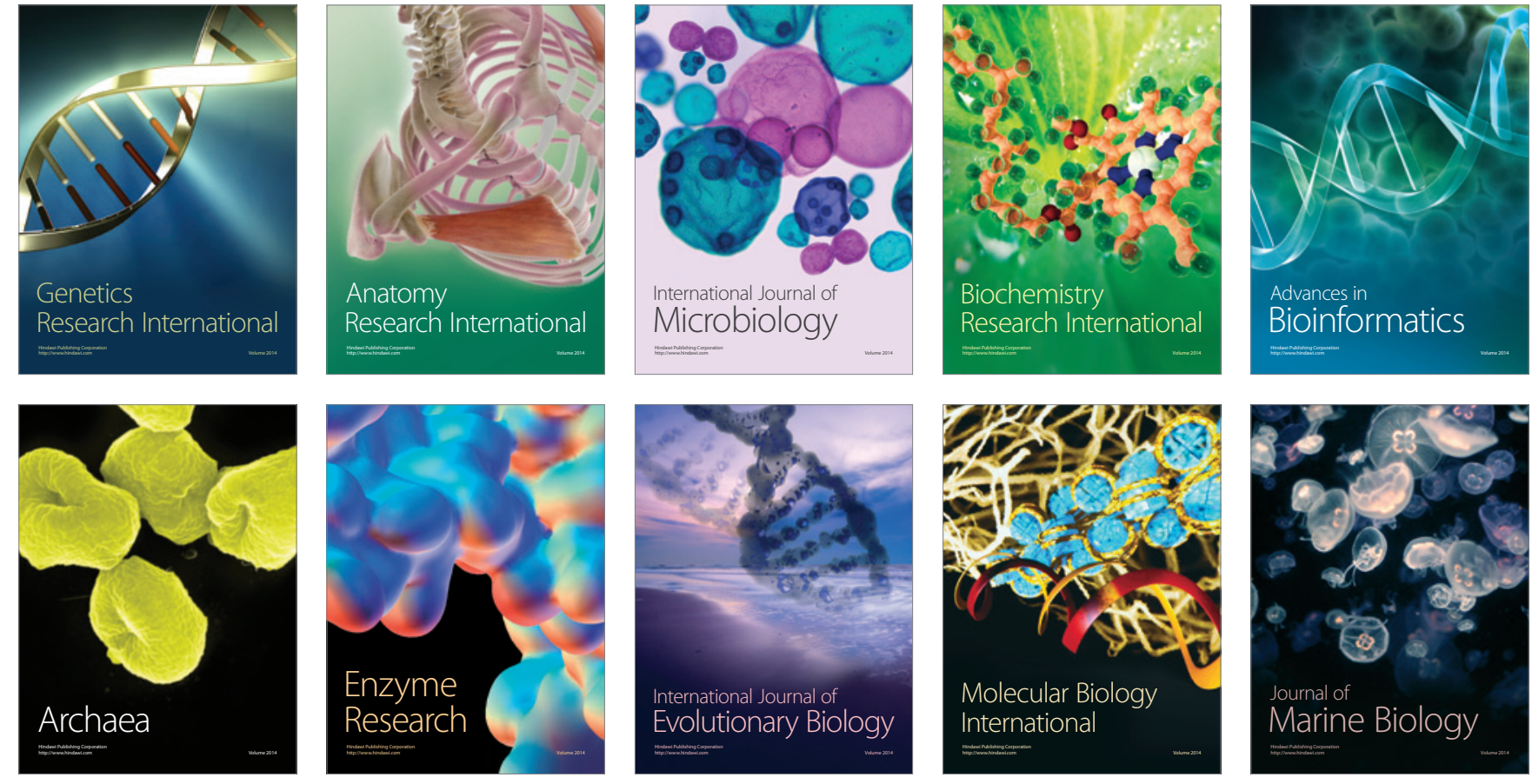